\title{
A New Purpose Built Spinal Injury Unit: Princess Alexandra Hospital, Ipswich Road, Woollooongabba, Brisbane, Queensland 4102, Australia
}

W. E. Davies, A.M., M.B., B.S., F.R.A.C.P., F.A.C.R.M.

Dr Davies has written to me as editor of Paraplegia, in December 1984 and has had subsequent correspondence with me, concerning his new custom-built 40 bedded Spinal Injury Unit, which is autonomous and self-contained, but has direct access to and is connected with the Princess Alexandra Hospital, in Brisbane, Queensland, Australia. The main hospital is a specialty hospital, which includes general surgery, general medicine and rehabilitation.

\section{Physical Facilities}

There are 40 beds, mainly four bedded rooms with two single bedrooms, and one six-bed area - for acute admissions - one of these beds being an isolation bed. All beds have full facilities such as oxygen, compressed air suction, and multiple power points. There is an Outpatient Department on the floor above the ground floor, which is also available for other departments; the administrative offices

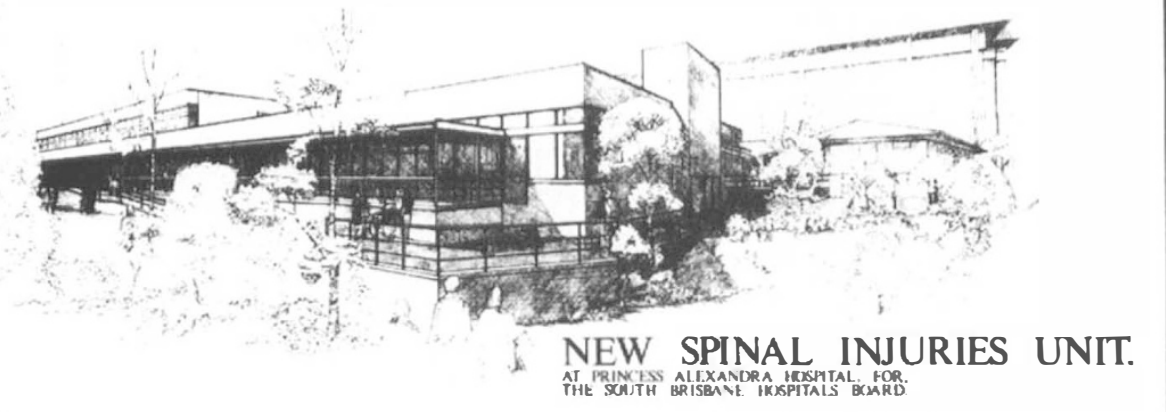

Figure 1 Architect's Impression of the New Unit. 


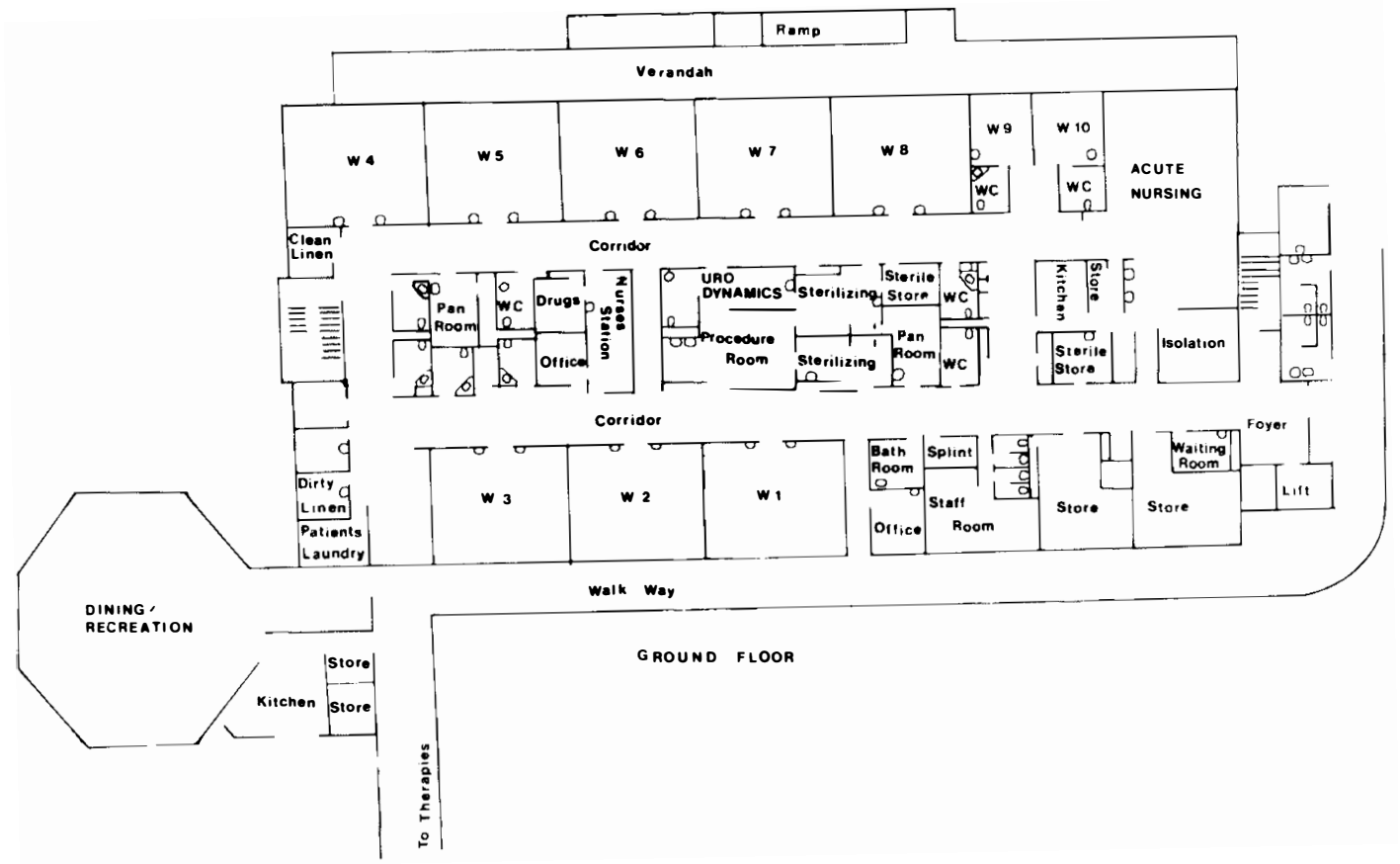

Figure 2 Ground Floor Plan of Unit.

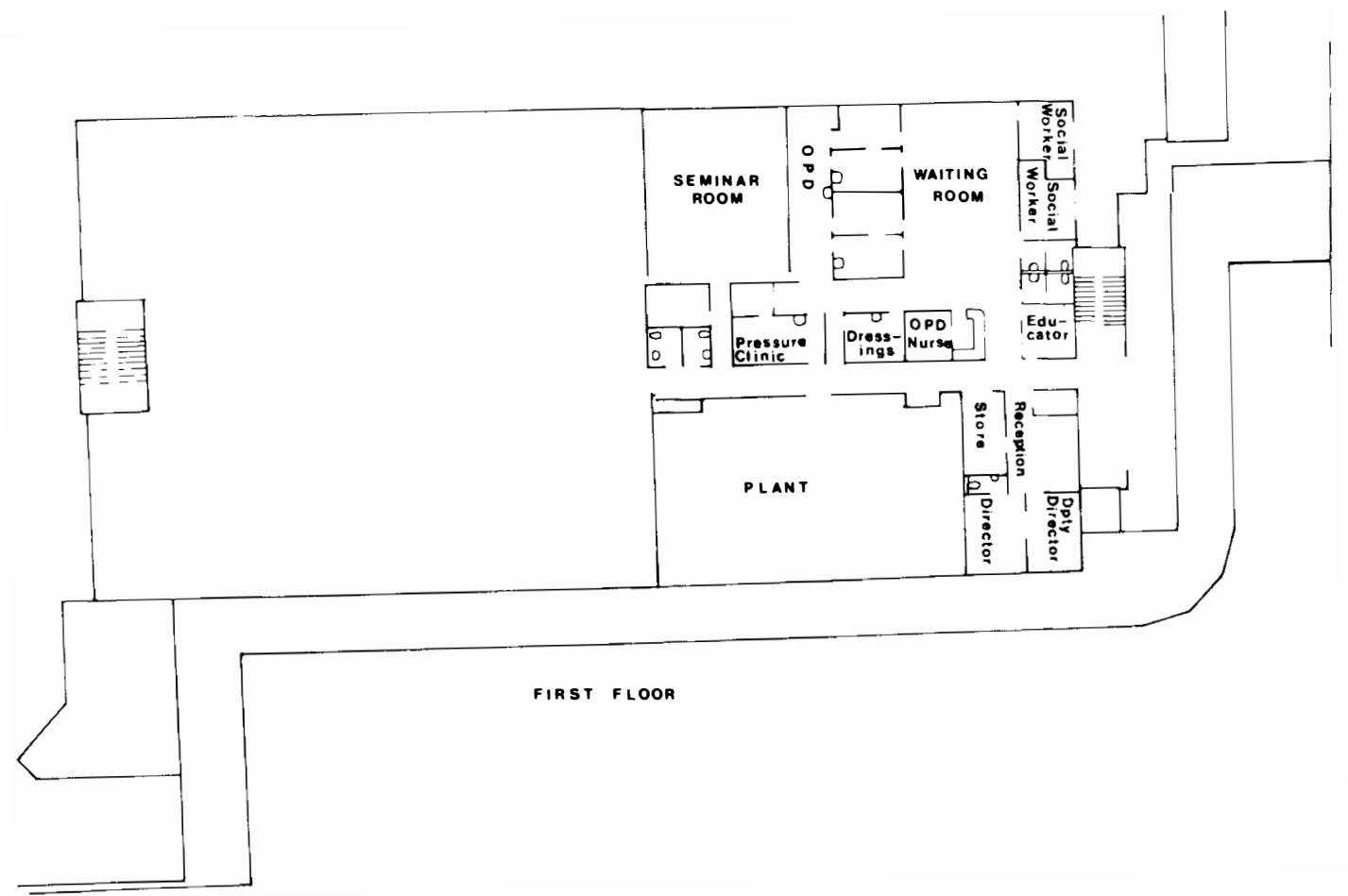

Figure 3 First Floor Plan. 
are also on this first floor, as is a large Conference Room. There is an Occupational Therapy Area and a Physiotherapy Gymnasium, which are separate from the Spinal Injury Unit itself. A large octagonal Dining Room is attached to the Ward Area. A central Urodynamic Laboratory is also located in the unit.

\section{Staffing}

\section{Medical}

This consists of a Medical Director, a Deputy Director and a Resident Medical Officer. Visiting specialists attend on a sessional basis, and these include a Neurosurgeon, Orthopaedic Surgeon, Urologist and a Plastic Surgeon.

\section{Nursing}

There are approximately 80 nursing staff, encompassing registered nurses, student nurses, enrolled nurses and orderlies.

\section{Paramedical}

There are three physiotherapists and three rotating physiotherapists; three occupational therapists and an occupational therapy aide; one social worker and another is being appointed.

\section{Functions}

This Unit is to care for all forms of paraplegic patients, but dominantly for those with traumatic spinal cord injuries. It admits more than 100 new patients a year and has about the same number of readmissions. Follow-up examinations take place in the Outpatient service and about one thousand such patients are being seen per year.

\section{Philosophy}

The aim is to admit patients to the Spinal Injury Unit directly from Casualty, unless they meet the criteria for admission to the Intensive Care Unit. About two-thirds of the admissions are referred from remote centres, more than 1000 miles away. The Spinal Centre serves the whole of the state of Queensland, which has a population of about $2 \frac{1}{4}$ million people. Transportation includes air transportation and if necessary, there is a retrieval team which flies from Brisbane in a twin engined air ambulance. Otherwise use is made of local aerial ambulances, commercial aircraft or the Flying Doctor Service. Patients coming from areas less than 200 miles distant arrive by road.

When the acute period of the patient's admission is over, the patient moves into the Rehabilitation Phase, which is part of the Spinal Injury Unit. 


\section{Research}

To date little has been done in this sphere, but a prospective examination of differences between conservative management of thoraco-lumbar fractures and the use of Harrington instrumentation techniques with segmental wiring and short segment grafting is being undertaken. Every second patient is being operated upon. So far, the results appear to indicate that there is virtually no difference in the end result of either method, even including the time spent in hospital. Dr Davies refers to a paper published in the American number of the fournal of Bone and Foint Surgery, which compared the results in Brisbane with those of the Spinal Paralysis Unit under the direction of Dr Jesse Dickson, Houston, Texas, U.S.A. The outcome of that study was that the only difference was the time spent in hospital, in that Dr Dickson's patients were discharged much earlier than those in Brisbane. But the criticism levelled at that paper, by Dr Davies was that the two groups were not completely comparable; a valid criticism. In the Brisbane prospective study, the same people doing the initial treatment and rehabilitation are treating both groups, and the patients are nonselected, so that every second patient is operated upon. Also any patient who gets out of phase, and requires surgery for a specific reason, or any patient who is not able to be operated upon for some particular reason, is deleted from the survey.

Phillip Harris Editor 